\title{
Method for differentiated enumeration of mixed cultures of thermophilic lactic acid bacteria and bifidobacteria by using only one culture medium
}

\author{
Paola Camaschella ${ }^{\mathrm{a}}$, Olivier Mignot ${ }^{\mathrm{b}}$, Franco Pirovano $^{\mathrm{a}^{*}}$, \\ Tomazo Sozzi ${ }^{\mathrm{a}}$
}

${ }^{a}$ Centro Ricerche Yomo, Sitia-YOMO SPA, Str per Merlino 3, 20060 Zelo Buon Persico (MI), Italy

${ }^{b}$ Nestlé Research Centre, Nestec Ltd, Vers-chez-les-Blanc, CH-1000 Lausanne 26, Switzerland

(Received 13 October 1995; accepted 1 December 1997)

\begin{abstract}
The dairy industry has recently prepared probiotic products containing, in addition to the specific yoghurt cultures, Lactobacillus acidophilus and bifidobacteria. Identification of the species and enumeration of the micro-organisms are easier for yoghurt cultures than for probiotic products containing Lactobacillus delbrueckii subsp. bulgaricus, Streptococcus thermophilus, bifidobacteria and Lactobacillus acidophilus. A new method has been developed using the commercially available $\mathrm{HHD}$ agar, which provides a morphological differentiation of colonies and a counting of single species on the same plate. Results obtained with HHD are very close to those obtained by the use of media specific for each strain (MRS, MRS at pH 5.4, MRS + dicloxacillin, M17). Instead of using many selective culture media, only one culture medium was used with saving of material and performance rapidity allowing the method to be applied to the routine controls of the probiotic products. (C) Inra/Elsevier, Paris
\end{abstract}

dairy product / lactic acid bacteria / bifidobacteria / HHD culture medium / separate enumeration

Résumé - Méthode pour le dénombrement différencié de cultures mixtes de bactéries lactiques thermophiles et de bifidobactéries en utilisant un seul milieu de culture. L'industrie laitière a récemment mis au point des produits probiotiques qui contiennent, en plus des cultures pour yaourt, Lactobacillus acidophilus et des bifidobactéries. L'identification des espèces et le dénombrement microbien sont plus faciles pour les cultures de yaourt que pour les produits probiotiques qui contiennent Lactobacillus delbrueckii subsp. bulgaricus, Streptococcus thermophilus, bifidobactéries et Lactobacillus acidophilus. Ce travail décrit une nouvelle méthode qui utilise seulement le milieu de culture HHD agar afin de différencier la morphologie des colonies et de dénombrer chaque espèce sur la même boîte. Les résultats du dénombrement microbien sur le milieu HHD agar sont très simi-

* Correspondence and reprints. 
laires à ceux qui ont été obtenus avec des milieux spécifiques pour chaque espèce (MRS, MRS à pH 5,4, MRS + dicloxacillin, M17). L'usage de l'agar HHD en remplacement de plusieurs milieux offre des avantages tels qu'une économie de matériels et une rapidité de dénombrement, et peut s'appliquer aux contrôles de routine des produits probiotiques. (C) Inra/Elsevier, Paris

produit laitier / bactérie lactique / bifidobactérie / milieu de culture HHD / dénombrement différencié

\section{INTRODUCTION}

In the dairy industry, starters of mixed cultures are used, among which the wellknown yoghurt culture, mixture of Lactobacillus delbrueckii subsp. bulgaricus and Streptococcus thermophilus. The introduction of probiotic micro-organisms is concerned with the manufacturing of new products containing, in addition to specific yoghurt cultures, Lactobacillus acidophilus and/or bifidobacteria $[2,4,11-14]$.

Since the products are prepared from many strains, they require a selective enumeration of different microbial species. While specific yoghurt microflora is easily identified by an officially recognized IDF method [8], for cultures different from yoghurt bacteria, the identification is quite difficult.

For counting $L$. acidophilus, the ECA medium (Esculin-Cellobiose Agar), as described by Hunger [6] and Lapierre [15], can not be applied because some strains are esculin-negative. Hence, several culture media based on modifications of MRS Agar [3], replacement of glucose with trehalose (MRS Agar with trehalose) [15] and use of maltose (modified MRS Agar) [5], have been tested but in these media, bifidobacteria also grow. Pedersen [18] describes a MRS Agar supplemented with bile that is able to inhibit the growth of yoghurt microflora and bifidobacteria. LA Agar [12] medium is specifically used for products containing $L$. acidophilus and bifidobacteria but it has been shown not to be selective for high contents of streptococci and other lactobacilli [18].
For the selective identification of bifidobacteria, a large number of media are also used $[1,17,19,20]$, such as MRS + dicloxacillin [22], Modified Selective Rogosa Agar [21], MGLP Agar [24], TOS Agar Medium [25], NPNL Medium [23] according to the IDF [9]. It was observed that the selectivity of these media is generally antibiotic-related and cell recoveries are low. Furthermore, many of them are not commercially available.

A method already developed for the differential enumeration of homofermentative and heterofermentative lactic acid bacteria provides the morphological differentiation of colonies in HHD Agar medium [16]. The differentiation of species is based on the use of a limited amount of fructose, as the only source of carbohydrates, and on the Bromcresol green, as an indicator. The species are recognizable from the different colour, as it was observed by MacDonald [16], and from the shape, appearance and sizes of the colonies.

The aim of this study is to determine the suitability of the HHD Agar medium for the detection and the specific enumeration of $S$. thermophilus, $L$. delbrueckii subsp. bulgaricus, L. acidophilus and bifidobacteria on the same plate.

\section{MATERIALS AND METHODS}

\subsection{Pure cultures}

Lactobacillus acidophilus LA1 and K8, Lactobacillus delbrueckii subsp. bulgaricus Lb170, Lb187 and Lb1, Streptococcus thermophilus S62 
and YS18 were obtained from Centro Sperimentale del Latte, Zelo B. Persico (MI) Italy.

Bifidobacterium infantis Bil, Bifidobacterium longum $\mathrm{B} 110$, Bifidobacterium breve $\mathrm{Bbr} 8$ were obtained from Prof. V. Scardovi, Ist. Microbiologia, Univ. di Bologna, Italy.

All strains were stored freeze-dried in a refrigerated room. $S$. thermophilus was cultured in sterilized milk $+0.1 \%$ yeast extract, inoculated at $1 \%$, incubated for $3 \mathrm{~h}$ at $42{ }^{\circ} \mathrm{C}, L$, delbrueckii subsp. bulgaricus in sterilized milk $+0.1 \%$ yeast extract, inoculated at $1 \%$, incubated for $5 \mathrm{~h}$ at $42{ }^{\circ} \mathrm{C}$, and $L$. acidophilus and bifidobacteria cultures in sterilized milk $+0.5 \%$ glucose $+1 \%$ yeast extract, inoculated at $1 \%$ and incubated for $15 \mathrm{~h}$ at $37^{\circ} \mathrm{C}$. Pure cultures were analysed once or several times starting from a fresh culture.

\subsection{Mixed cultures}

Yoghurt: 10 samples.

Probiotic fermented milk containing $S$. thermophilus, $L$ delbrueckii subsp. bulgaricus, $L$ acidophilus and bifidobacteria spp. or some of them: 15 samples.s

Freeze-dried probiotic products containing $S$. thermophilus, L. delbrueckii subsp. bulgaricus, L. acidophilus and bifidobacteria spp. or some of them: 19 samples.

\subsection{Media}

HHD (dehydrated: Lactic Acid Bacteria Differential Broth, Cod M1086 from HI Media Laboratories Pvt Limited, Bombay - 400086 , India) from MacDonald et al. [16].

All ingredients, except for Tween 80 were dissolved by heating, then Tween 80 was added; the medium was sterilized in an autoclave at $121{ }^{\circ} \mathrm{C}$ for $15 \mathrm{~min}$. Just before use, the medium was melted and distributed in plates of $90 \mathrm{~mm}$ diam $(12 \mathrm{~mL} /$ plate $)$ and left to solidify. The plates were maintained in laminar flows for drying for $20 \mathrm{~min}$.

The following commercially available media were used as reference: MRS Agar (DIFCO) for L. acidophilus [3]; MRS Agar (DIFCO) at $\mathrm{pH} 5.4$ for $L$. delbrueckii subsp. bulgaricus (IDF Standard 117A [8]); MRS Agar (DIFCO) Dicloxacillin (Sigma) for bifidobacteria [22]; M17 Agar (DIFCO) for S. thermophilus [8].

\subsection{Procedure}

Forty samples were analysed for each microbial species. To perform the analysis, samples were diluted $1: 10$ with peptone/saline solution and homogenized in Stomacher for $1 \mathrm{~min} 30 \mathrm{~s}$; then decimal dilutions were prepared [10]. Inoculation in HHD was carried out by spreading $0.1 \mathrm{~mL}$ of the decimal dilutions to the surface of each plate. Incubation occurred anaerobically at $37^{\circ} \mathrm{C}$ for 3 days in Gas Pak with $\mathrm{CO}_{2}$ and $\mathrm{H}_{2}$ atmosphere.

Enumerations in control medium were carried out by the pour plate method of $1 \mathrm{~mL}$ of dilution and incubated at $37^{\circ} \mathrm{C}$ for $48 \mathrm{~h}$ in M17 Agar for $S$. thermophilus and anaerobically in GasPak at $37^{\circ} \mathrm{C}$ for $72 \mathrm{~h}$ for other culture media.

After incubation, colonies were counted in all media and in HHD by separating the species through the different morphology of the colonies both with the naked eye and at stereoscopic microscopy Wild-M8 (Leitz) (oculars 10 $\times$, lens 5-50 $\times$ ) and expressed as CFU (Colony-Forming Units) $\cdot \mathrm{g}^{-1}$.

The results were confirmed by examining under the microscope (Zeiss oculars $10 \times$, lens $100 \times$ ) the square root of colonies on the plates.

\subsection{Photos}

Photos of colonies were made with stereoscopic microscopy in a dark room with a Minolta X-300S camera, with film for artificial light 160 ASA at the tungsten with microscopic magnification $120 \times$.

\subsection{Statistical analysis}

After logarithmic transformation of the results to normalize the distribution, the statistical analyses were perfomed according to the IDF [7] using the software Lotus 1-2-3. The regression equation $\mathrm{y}=\mathrm{ax}+\mathrm{b}$ was calculated, where $\mathrm{y}$ refers to counts on reference medium and $x$ to those on HHD medium. The accuracy of $y$ was estimated by $\mathrm{s}_{\mathrm{y} . \mathrm{x}}$, the residual standard deviation of the regression. Counts of both media were compared using Students $t$-test applied to $\mathrm{d}_{\mathrm{m}} /\left(\mathrm{s}_{\mathrm{d}} / \mathrm{n}^{1 / 2}\right)$, where $d_{m}$ is the mean of $d=y-x, s_{d}$ is the standard deviation of $d$ and $n$ the number of samples. 


\section{RESULTS AND DISCUSSION}

\subsection{Colony morphology on reference media}

The colonies of bifidobacteria in MRS Agar, MRS Agar at pH 5.4 and MRS Agar Dicloxacillin were of white-cream colour, of lenticular shape with regular sides. Colonies of $L$. delbrueckii subsp. bulgaricus in MRS Agar or in MRS Agar at pH 5.4 were circular or trilobate, of white-cream colour with an external fluffy ring which may be examined under the stereoscopic microscope or with a magnifier. This ring was not found in the colonies of $L$. acidophilus that are much more irregular shaped than those of L. delbrueckii subsp. bulgaricus.

Colonies of S. thermophilus in M17 Agar as well as in MRS Agar were white-cream coloured, lenticular, with regular sides. The colonies were recognizable from those of lactobacilli and bifidobacteria since they were very small in this second culture medium.

For the enumeration of specific yoghurt cultures, these media allow a good selectivity and are generally applied without problems as reference test.

\subsection{Colony morphology on HHD Agar medium}

The different strains of the same species showed a similar morphology on HHD, while the 4 species under examination had a clearly different morphology. Only $S$. thermophilus exhibited 2 different morphologies which were both well recognizable.

Colony morphology of the 4 species on HHD Agar medium is shown in figures 1-5. Colonies of $S$. thermophilus appeared as follows: type 1) generally small, circular, smooth and almost transparent (figure 1); type 2) eircular, convex and dark green coloured (figure 2).

Colonies of bifidobacteria were similar in size to those of $S$. thermophilus, but they appeared translucent, convex like a drop of water (figure 3 ). Colonies of $L$. delbrueckii subsp. bulgaricus were large, of irregular shape, with flat surface, regular bright green with internal undulatory streaking (figure 4). Colonies of $L$. acidophilus were large, of irregular shape, convex and pyramid shaped surface, light brown with a small central spot of dark green colour (figure 5).

Mixed cultures of different species are shown in figure 6. It was observed that the morphology of the colonies was typical for each species and was still well recognizable when cultures developed together.

The medium did not maintain its original colour but changed from blue to green, green-yellow and yellow depending on the development of acidifying colonies on the plate. This is due to the bromcresol green that has a $\mathrm{pK}$ value of 4.6 .

Sizes of colonies varied depending upon the number of colonies developed on the plate: bifidobacteria and $S$. thermophilus generally were of similar sizes, while $L$. delbrueckii subsp. bulgaricus as well as $L$. acidophilus were larger than the others.

The use of HHD medium allowed the 4 different species to be distinguished even though the colonies showed a difference of 4-5 orders of magnitude: the colonies of the most dominant species built a carpet from which the subdominant colonies stand out and could be easily distinguished.

\subsection{Comparison of counts on HHD agar and reference media}

Counts on HHD and refence media were very well correlated for the 4 species (table I). Moreover, values of $s_{d}$ were very close to the corresponding values of $\mathrm{s}_{\mathrm{y}, \mathrm{x}}$ (standard deviation from the regression), which shows the similarity of results with both methods [7]. However, counts on HHD were slightly, but significantly higher than those on reference media for the 4 species, as indicated by the $t$ values (table $I$ ). HHD medium, 


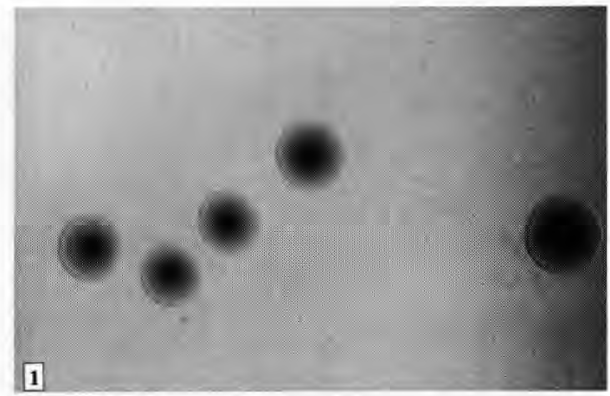

Figure 1. Morphology of colonies of Streptococcus thermophilus - type 1 , made with stereoscopic microscopy (120 $\times$ magnification).

Figure 1. Morphologie des colonies de Streptococcus thermophilus - type 1 , faites par microscopie stéréoscopique (grossissement $\times 120$ ).

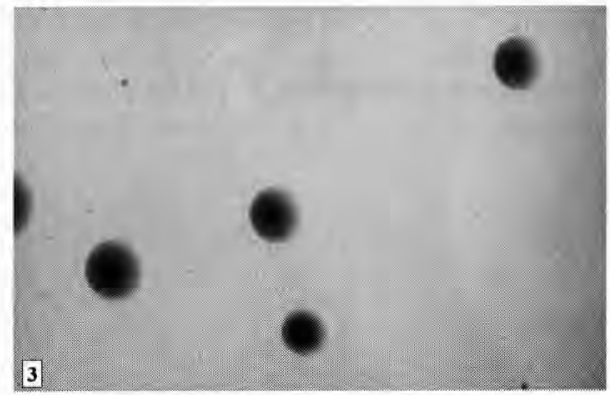

Figure 3. Morphology of colonies of bifidobacteria, made with stereoscopic microscopy (120x magnification).

Figure 3. Morphologie des colonies de bifidobactéries, faites par microscopie stéréoscopique (grossissement $\times 120$ ).

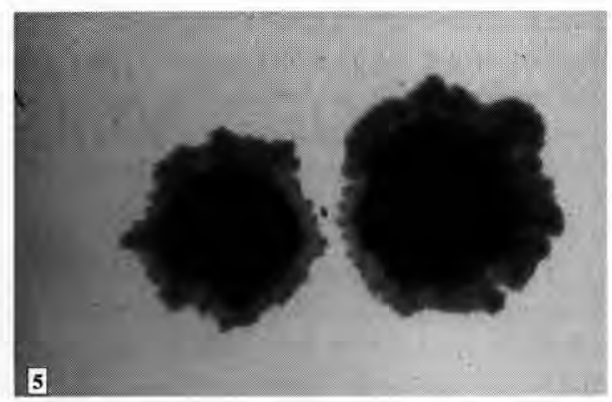

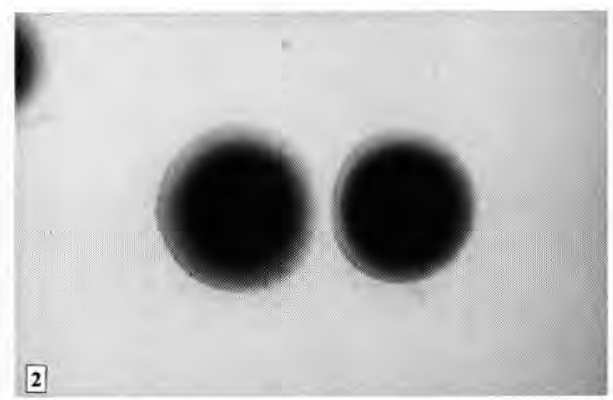

Figure 2. Morphology of colonies of Streptococcus thermophilus - type 2 , made with stereoscopic microscopy ( $120 \times$ magnification).

Figure 2. Morphologie des colonies de Streptococcus thermophilus - type 2 , faites par microscopie stéréoscopique (grossissement $\times 120$ ).

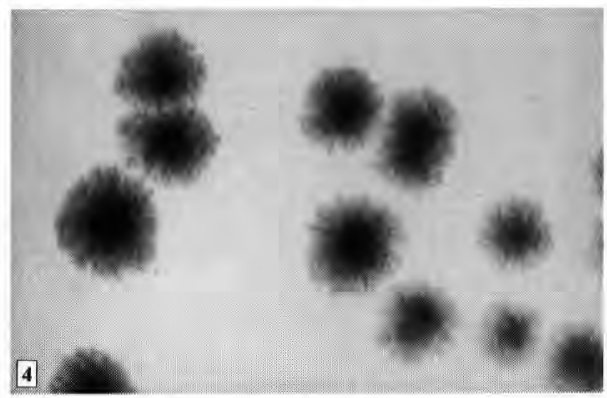

Figure 4. Morphology of colonies of Lactobacillus delbrueckii subsp. bulgaricus, made with stereoscopic microscopy (120 $\times$ magnification).

Figure 4. Morphologie des colonies de Lactobacillus delbrueckii subsp. bulgaricus, faites par microscopie stéréoscopique (grossissement $\times$ 120).

Figure 5. Morphology of colonies of Lactobacillus acidophilus, made with stereoscopic microscopy $(120 \times$ magnification).

Figure 5. Morphologie des colonies de Lactobacillus acidophilus, faites par microscopie stéréoscopique (grossissement $\times 120$ ). 


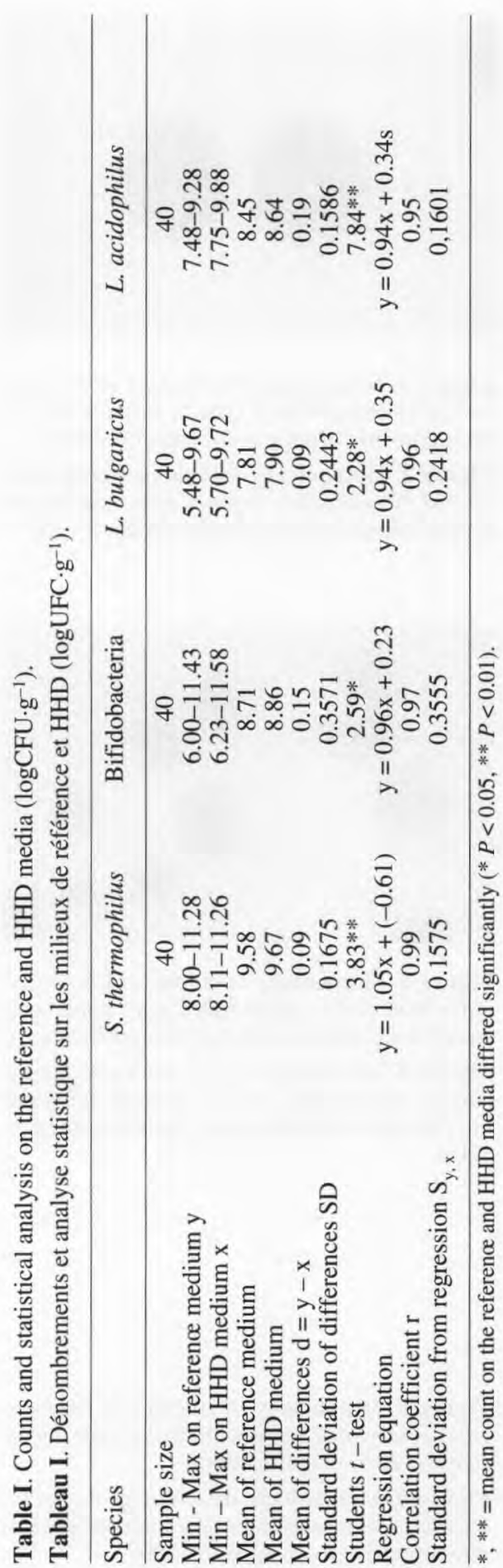

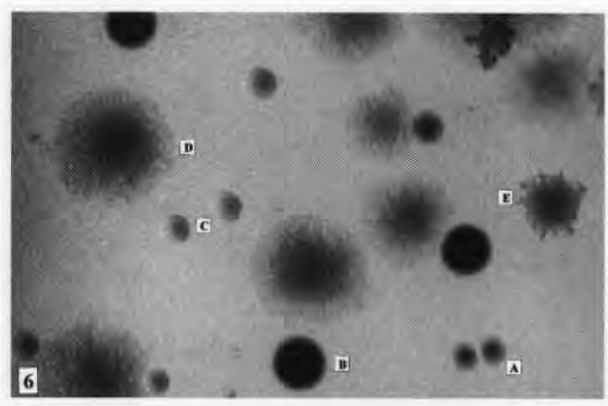

Figure 6. Morphology of colonies of mixed cultures, made with stereoscopic microscopy (120 $\times$ magnification). A. Streptococcus thermophilus type 1. B. Streptococcus thermophilus type 2. C. Bifidobacteria. D. Lactobacillus delbrueckii subsp. bulgaricus. E. Lactobacillus acidophilus.

Figure 6. Morphologie des colonies des cultures mixtes faites par microscopie stéréoscopique (grossissement $\times 120$ ). A. Streptococcus thermophilus type 1. B. Streptococcus thermophilus type 2. C. Bifidobacteria. D. Lactobacillus delbrueckii subsp. bulgaricus. E. Lactobacillus acidophilus.

which is not a selective medium, allowed in particular a better recovery of $L$. acidophilus $(+0.19 \log )$ and bifidobacteria $(+0.15 \mathrm{log})$.

\section{CONCLUSIONS}

The main advantage of the method is the use of only one culture medium to enumerate $S$. thermophilus, $L$. delbrueckii subsp. bulgaricus, L. acidophilus and bifidobacteria in mixed cultures containing these species in different amounts with consequent performance rapidity, savings of material and economic profit.

The commercially available HHD Agar medium can be applied for the enumeration of these 4 species in the routine controls of dairy and probiotic products. 


\section{REFERENCES}

[1] Beerens H., An elective and selective isolation medium for Bifidobacterium spp., Lett. Appl. Microbiol. 11 (1990) 155-157.

[2] Dellaglio F., Torriani S., Vlaeminck G., Cornet R., Specific characteristics of microorganisms used for new fermented milks, Bull. Int. Dairy Fed. 277 (1992) 4-16.

[3] De Man J.C., Rogosa M.E., Sharpe M.E., A medium for the cultivation of lactobacilli, J. Appl. Bacteriol. 23 (1960) 130-135.

[4] Fonden R., Lactobacillus acidophilus, in: Fermented milks - current research, Congrès international, 14-16 December 1989, Paris, France, John Libbey Eurotext Ltd, Paris, 1989, pp. $35-40$.

[5] Hull R.R., Roberts A.V., Differential enumeration of Lactobacillus acidophilus in yoghurt, Aust. J. Dairy Technol. 39 (1984) 160-163.

[6] Hunger W., Aesculin-Cellobiose-Agar für die Isolierung und Keimzahlbestimmung von Lactobacillus acidophilus, Milchwissenschaft 41 (1986) 283-285.

[7] IDF, Milk. Enumeration and evaluation of the overall accuracy of indirect methods of milk analysis - application to calibration procedure and quality control in dairy laboratory, Standard 128 (provisional'), 1985.

[8] IDF, Yoghurt enumeration of characteristic microorganisms - colony count technique at $37^{\circ} \mathrm{C}$, Standard $117 \mathrm{~A}, 1988$.

[9] IDF, Lactic acid starters. Standard of identity, Standard 149 (provisional'), 1991.

[10] IDF, Milk and milk products. Preparation of samples and dilutions for microbiological examination, Standard 122B, 1992.

[11] Klupsch H.J., Bioghurt-Biogarde-acidified milk products with optimum qualities, North Eur. Dairy J. 49 (1983) 29-32.

[12] Klupsch H.J., Säure Milcherzeugnisse-Milchmischgetränke und Desserts, Verlag Th. Mann, Gelsenkirchen-Buer, 1984, p. 362.

[13] Klupsch H.J., The technology for producing fermented milk products using $L$. acidophilus and bifidus bacteria, Eur. Dairy Mag. 14 (1990) 22-24.
[14] Kurmann J.A., Starters for fermented milks: starters with selected intestinal bacteria, Bull. Int. Dairy Fed. 227 (1988) 41-55.

[15] Lapierre L., Growth of Lactobacillus acidophilus isolated from fermented dairy products on different selective media, Research paper, Nestlé, Vevey, 1990.

[16] MacDonald L.C., McFeeters R.F., Daeschel M.A., Fleming H.P., A differential medium for the enumeration of homofermentative and heterofermentative lactic acid bacteria, Appl. Environ. Microbiol. 53 (1987) 1382-1384.

[17] Munoa F.J., Pares R., Selective medium for isolation and enumeration of Bifidobacterium ssp., Appl. Environ. Microbiol. 54 (1988) 1715-1718.

[18] Pedersen L.W., Proposed methods for counting and discriminating between: $L$. acidophilus, L. delbrueckii subsp. bulgaricus, S. thermophilus and bifidobacteria, Research paper, Chr. Hansen's Laboratory, Milwaukee, 1993.

[19] Rasic J.L., Culture media for detection and enumeration of bifidobacteria in fermented milk products, Bull. Int. Dairy Fed. 252 (1990) 24-31.

[20] Resnick J.G., Levin M.A., Quantitative procedure for enumeration of bifidobacteria, Appl. Environ. Microbiol. 42 (1981) 427-432.

[21] Shimada K., Mada N., Mutai M., Suzuki A., Konuma $\mathrm{H}$., Techniques for viable cell counts of bifidobacteria in fermented milks, J. Food Hyg. Soc. Jpn 18 (1977) 537-541.

[22] Sozzi T., Brigidi P., Mignot O., Matteuzzi D., Use of dicloxacillin for the isolation and counting of bifidobacteria from dairy products, Lait 70 (1990) 357-361.

[23] Teraguchi S., Uehara M., Ogasa K., Mitsuoka T., Enumeration of bifidobacteria in dairy products, Jpn J. Bacteriol. 33 (1978) 753-761.

[24] Teraguchi S., Kawashima T., Kuboyama M., Test tube method for counting bifidobacteria in commercial milk products and pharmaceutical bacteria products, J. Food Hyg. Soc. Jpn 23 (1982) 39-44.

[25] Wijsman M.R., Hereijgers J.L.P.M., De Groote J.M.F.H., Selective enumeration of bifidobacteria in fermented dairy products, Neth. Milk Dairy J. 34 (1989) 395-405. 